\title{
HIV-associated peripheral neuropathies: a review
}

\author{
Iyagba $A^{1}$, Onwuchekwa $A^{2}$ \\ ${ }^{1}$ Dr. Alagoma Iyagba, Professor, ${ }^{2}$ Dr. Arthur Onwuchekwa, both authors are affiliated with Department of Internal \\ Medicine, University of Port Harcourt Teaching Hospital, Port Harcourt, Rivers State, Nigeria.
}

Address for Correspondence: Dr. Alagoma Iyagba, E-Mail: amiyagba@gmail.com

\begin{abstract}
Objective: To review the various neurologic complications of HIV. Methods: A MEDLINE search of the Englishlanguage literature using a combination of words (HIV, neuropathy and diagnosis) was used to identify original studies, consensus statements and reviews published in the last 25 years. Results: The various HIV-associated neuropathies are described. Conclusion: It is important for clinicians to be equipped with the knowledge of the various neuropathic complications of HIV. Prompt diagnosis of these with institution of proper treatment measures would go a long way towards reducing morbidity and mortality outcomes.
\end{abstract}

Keywords: HIV, neurologic, distressing neuropathic.

\section{Introduction}

Human immunodeficiency virus (HIV) neuropathy has varied effects on the nervous system []. Peripheral neuropathy is the most common neurological complication of HIV infection. It is not commonly seen in the early stages of HIV infection, mostly affecting persons with a CD4 count less than 200 cells/ $\mu \mathrm{ml}$ [].

Peripheral neuropathy causes disability and negatively impairs their quality of life by causing distressing neuropathic pain []. It is important for clinicians to be knowledgeable about various neuropathies that could occur with HIV as these could erroneously be attributed to other disease processes. This article focuses on the various neuropathies that may be seen in HIV-infected individuals.

Distal symmetrical polyneuropathy neuropathy- Distal symmetrical polyneuropathy neuropathy (DSPN) is the most common peripheral neuropathy in patients with HIV infection [,]. Though not life threatening, it greatly affects their quality of living. It could be confused with antiretroviral toxic neuropathy which may arise from use of agents with neurotoxic side-effects such as zalcitabine and didanosine []. DSPN could further limit the use of these neurotoxic antiretroviral drugs in these individuals. Being so common, there is the possibility of attributing all symptoms and signs of peripheral neuropathy to it without adequate investigation to identify other treatable neuropathies [].

It presents classically with sensory loss that starts from the distal feet, ascending progressively upwards to involve the hands in advanced stages of the disease. They describe an area of sensory abnormality that may manifest with numbness, pins and needles or tingling feelings. Distressing neuropathic pain which is usually worse at night may be present. There is usually just a mild involvement of the muscles of the feet. Intrinsic hand muscle function is usually well preserved until late in the disease. There is usually an equal impairment of all modalities of sensory function in the feet and hands. Ankle tendon reflexes are usually sluggish or absent. Knee reflexes are normal. However, the presence of an exaggerated knee jerk may indicate the co-existence of a central nervous system disorder such as myelopathy []. The main stay of treatment is relief of neuropathic pain with agents such as pregabalin. Highly active antiretroviral therapy (HAART)

Manuscript received $24^{\text {th }}$ October 2016

Reviewed: $4^{\text {th }}$ November 2016

Author Corrected: $15^{\text {th }}$ November 2016

Accepted for Publication $30^{\text {th }}$ November 2016 
may improve symptoms in some persons []. Concurrent neurotoxic medications used for treating HIV- associated conditions such as isoniazid, metronidazole, dapsone may need to be discontinued []. Clinical trials with potentially neuro-regenerative therapies such as nerve growth factor, prosaptide, and timocdar that were neurotrophic in animal models have failed [,,]. Carnitine, an essential fatty acid has shown benefits in some individuals. It acts by increasing the pool of fatty acids necessary for mitochondrial function and also stimulating nerve growyh factor []. There is some evidence that carnitine is important for the regeneration of peripheral nerve after injury [].

Table: HIV-associated peripheral neuropathies.

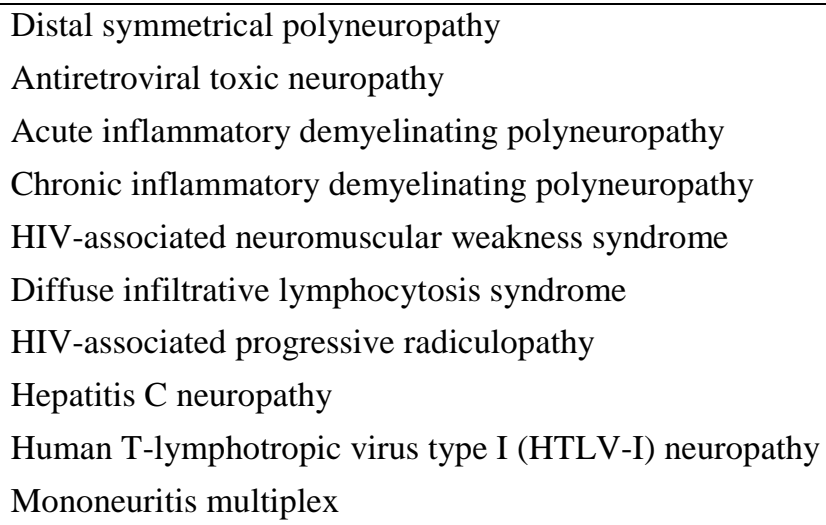

Antiretroviral toxic neuropathy- This has a similar clinical manifestation with HIV-DSPN. It occurs in persons treated with didanosine, zalcitabine, and stavudine. The toxic effects of nucleoside reverse transcriptase inhibitors are dose dependent [,,]. It is indistinguishable from HIV-induced DSPN on clinical examination or nerve conduction studies []. Elevated serum lactate has been shown to be a marker for stavudine-related neuropathies []. Nucleoside neuropathy develops gradually usually three months after commencement of the agent [].

Proposed mechanisms for its pathogenesis include: direct mitochondrial toxicity [], downregulation of gene for expression of brain-derived neurotrophic factor in the dorsal root ganglion [] and competitive inhibition of human mitochondrial DNA polymerase-gamma []. Genetic polymorphisms may predispose to nucleoside neuropathy []. Discontinuation of the drug is the recommended treatment. Improvement in symptoms may occur within a period of six weeks-six months [].

An increased risk of DSPN has also been reported in persons treated with the protease inhibitors: indinavir, saquinavir, and ritonavir []. There neurotoxicity may be due to inhibition of mitochondrial DNA polymerase [,,].

Acute inflammatory demyelinating polyneuropathy- Acute inflammatory demyelinating polyneuropathy (AIDP) or Guillain-Barre syndrome may occur at seroconversion or asymptomatic stages of HIV infection []. It is rarely seen with immune reconstitution following highly active antiretroviral therapy []. It typically presents with symmetrical ascending lower limb weakness with sparing of the sensory system. There could also be respiratory insufficiency due to involvement of the thoracic spinal nerves. Rarely, the cranial nerves may be involved. Autonomic nervous system involvement may lead to fluctuations in blood pressure and life threatening arrhythmias.

The clinical manifestations are usually not different from those of HIV-negative individuals [].

Nerve conduction studies shows reduction of conduction velocity, conduction block, prolonged distal latencies, temporal dispersion, and late responses []. The demyelinating form of the disease is usually more common than the axonal variant []. Magnetic resonance imaging (MRI) of the spine is usually done to exclude a mass lesion or infiltrative lesions of the nerve roots. MRI may be normal or show nerve root enhancement Cerebrospinal fluid (CSF) analysis usually shows raised protein and few cells (pleocytosis), of up to $50 \mu \mathrm{H} 50 / \mu \mathrm{L}$. This is unlike the case in normal individuals where the CSF protein in markedly elevated with no cells (albuminocytologic dissociation) []. 
Chronic inflammatory demyelinating polyneuropathy- Chronic inflammatory demyelinating polyneuropathy (CIDP) usually presents late in the course of HIV infection. CD4+ lymphocyte counts are less than 50 cells/ $\mu \mathrm{L}$ []. It is slowly progressive with a relapsing-remitting course unlike HIV-associated acute inflammatory demyelinating polyneuropathy []. It lacks the autonomic features seen with HIV-associated AIDP. Weakness is found in both distal and proximal muscles of the upper and lower extremities. Tendon reflexes are sluggish or absent. Distal sensory abnormalities are often mild compared with the weakness. Patients with severe generalized weakness may have facial diplegia, bulbar weakness, and respiratory insufficiency []. Treatment is similar to that of HIV-negative individuals.

HIV-associated neuromuscular syndrome- HIV-associated neuromuscular weakness syndrome is a newly described syndrome associated with NRTI-treated patients characterized by hyperlactatemia, nausea and vomiting, hepatomegaly and progressive weakness []. Motor weakness develops rapidly in days or weeks and evolves into respiratory failure and death including Guillain-Barre syndrome. Simpson et al [], found a variable range of neuromuscular involvement in a series involving sixty-nine patients ranging from progressive sensorimotor polyneuropathy with electrophysiological and pathologic predominant axonal damage to myopathy with muscular inflammatory infiltration.

Diffuse infiltrative lymphocytosis syndrome- This is a rare form of sensorimotor neuropathy characterized by persistent polyclonal peripheral blood CD8+ lymphocytosis with infiltration of several organs (liver, spleen, kidneys, salivary glands) including the peripheral nerves []. It presents clinically as an acute or sub-acute painful multi-focal most often symmetrical neuropathy []. It occurs many years after seroconversion and is thought to be due to excessive host response to the virus []. Nerve biopsy shows marked angiocentric CD8+ infiltrates without vessel wall necrosis []. The electrophysiological study shows features of an axonal neuropathy. It responds well to HAART [].

Hepatitis C neuropathy- The hepatitis $\mathrm{C}$ virus rarely leads to neurological complications []. However with the rising incidence of HIV/Hepatitis $\mathrm{C}$ co-infection there is likely to be an increase in hepatitis $\mathrm{C}$ related complications including neuropathy because hepatitis $\mathrm{C}$ viral load increases as HIV infection advances []. Two forms of neuropathy have been identified: a distal symmetrical sensory neuropathy (more commonly seen) and a mononeuritis multiplex []. Interferon used in the treatment of hepatitis $\mathrm{C}$ viral infection may worsen the neuropathy [].

HIV-associated progressive polyradiculopathy- This manifests with a radicular pattern of motor and sensory changes. It is due to infection of the cauda equina leading to inflammation and necrosis of the lumbosacral nerve roots []. It could be caused by cytomegalovirus, tuberculosis, neurosyphilis, lymphomatous meningitis [,]. Of these aetiologies, cytomegalovirus is the commonest []. Gadolinium-enhanced MRI of the lumbosacral spine may be normal or show meningeal enhancement in the cauda equine []. MRI is also necessary to exclude compressive lesions of the cauda equine. It is necessary to exclude focal compressive lesions of the cauda equina. Cerebrospinal fluid (CSF) findings in CMV-related polyradiculopathy include low glucose, elevated protein, and ‘ prominent polymorphonuclear pleocytosis. However, a normal CSF does not exclude the diagnosis [,]. Electrodiagnostic studies show evidence of a severe axonal polyradiculopathy with extensive denervation of lower extremity muscles on needle electromyography [].

Human T-lymphotropic virus type I neuropathy- A myelopathy is well recognized complication arising from infection with the human T-lymphotropic virus type I (HTLV-I.). However, some individuals also develop a distal symmetrical sensory peripheral neuropathy indistinguishable from that caused by the HIV []. The peripheral manifestations of this neuropathy are usually obscured by the co-existing myelopathy [].

HTLV-I causes an axonal and demyelinating neuropathy []. Individuals with HIV/HTLV-I co-infection have a much higher incidence of peripheral neuropathy than HIV-infected persons []. A case report revealed the efficacy of steroids in treating a dually infected patient [].

Mononeuritis multiplex- Mononeuritis multiplex in HIV infection could be immune mediated or secondary to a vasculitis. Immune mechanisms are supported by the presence of immunoglobulin deposits, complement, and immune complexes on the vessel wall []. A direct viral invasion of the peripheral nerve is supported by isolation of the virus from peripheral nerve homogenates []. 
Histopathologic studies of affected nerves reveal evidence of epineural and endoneural perivascular inflammatory infiltrates []. Some patients have evidence of a necrotizing vasculitis. The clinical presentation is similar to that in nonHIV infected individuals. Multifocal motor and sensory abnormalities develop over days to weeks. Intravenous immunoglogbulins and steroids are effective for treatment.

\section{Conclusion}

It is important for clinicians to be knowledgeable about the various peripheral neuropathies seen in HIV. Prompt diagnosis and recognition of these with the institution of appropriate treatment measures would go a long way towards reducing morbidity and mortality outcomes.

Acknowledment: We thank Dr. Godspower Asekomeh his guidance during the preparation of this manuscript.

Funding: Nil, Conflict of interest: None initiated, Permission from IRB: Yes

\section{References}

1. Marco CA, Rothman RE. HIV infection and complications in Emergency Medicine. Emergency Med Clinic North Am. 2008; 26(2):367-387.

2. Sevigny J, Estanislao L.HIV Neurology. In: Current Medical Diagnosis and Treatment 2008. Brust CMJ (Ed), Lange Medical Books 2007, pp 463.

3. Ellis RJ, Rosario D, Clifford DB, McArthur JC, Simpson D, Alexander $\mathrm{T}$, et al. Continued high prevalence and adverse clinical impact of human immunodeficiency virus-associated sensory neuropathy in the era of combination antiretroviral therapy: the CHARTER Study. Arch Neurol. 2010; 67(5):552-8.

4. Jakobsen J, Smith T, Gaub J, Helweg-Larsen S, Trojaborg W. Progressive neurological dysfunction during latent HIV infection. BMJ. 1989; 299 (6693):225-228.

5. Chavanet P, Giroud M, Lancon J, Borsotti JP, Waldner-Combernou AC, Pillon D et al. Altered peripheral nerve conduction in HIV-patients. Cancer Detect Prev. 1988; 12:249-255.

6. Carr A, Cooper DA. Adverse effect of an antiretroviral therapy. The Lancet. 2000; 356(9239): 1423-1430.

7. Sadler M, Nelson M .Peripheral neuropathy in HIV. Intl J STD and AIDS. 1997; 8(1):16-22.
8. Singer EJ, Valdes M, Commins D, Levine A. Neurologic presentations of AIDS. Neurol Clin. 2010; 28(1):253-275

9. Martin C, Solders G, Sonnerborg A, Hanson P. Antiretroviral therapy may improve sensory function in HIV-infected patients: a pilot study. Neurology. 2000; 54 (1):2120-7.

10. Estanislao L. HIV myelopathy, peripheral neuropathy and myopathy. In: Clinical Neurovirology, Nath ABJ, (Ed). 2003, Informa Healthcare, New York, pp. 283.

11. Schifitto G, Yiannoustous C, Simpson DM, Adornato BT, Singer EJ, Hollander H, et al. Long-term treatment with recombinant nerve growth factor for HIV associated sensory neuropathy. Neurology. 2001; 57(7):1313-1316.

12. Evans SR, Simpson DM, Kitch DW, King A, Clifford DB, Cohen BA, et al. A randomized trial evaluating Prosaptide for HIV- associated sensory neuropathies: use of an electronic diary to record neuropathic pain. PLoS ONE. 2007; 2(7):6: e551.

13. Hahn K, Sirdofsky M, Brown A, Ebenezer G, Hauer $\mathrm{P}$, Miller $\mathrm{C}$, et al. Collateral sprouting of human epidermal nerve fibers following intracutaneous axotomy. J Peripheral Nerv Syst. 2006; 11(2): 142-7.

14. Petorrossi VE, Brunetti V, Carrobi C DellaTorre G, Grassi S. L-acetyl carnitine enhances functional muscle reinnervation. AIDS. 1997; 11(2):185-190.

15. De Grandis D, Santoro L, Di Benedetto P. L-acetyl carnitine in the treatment of painful peripheral neuropathies in $\mathrm{HIV}+$ patients. Clinical Drug Investigation. 1995; 10(6):317-322.

16. Cherry CL, McArthur JC, Hoy JF, Wesselingh SL. Nucleoside analogues and neuropathy in the era of HAART. J Clinical Virol. 2003; 26(2):195-207. 
17. Fichtenbaum CJ, Clifford DB, Powderly WG. Risk factors for dideoxynucleoside-induced toxic neuropathy in patients with the human immunodeficiency virus infection. JAIDS. 1995; 10(2):169-174.

18. Moore RD, Wong WM, Keruly JC, McArthur JC. Incidence of neuropathy in HIV-infected patients on monotherapy versus those on combination therapy with didanosine, stavudine and hydroxyurea. AIDS. 2000; 14(3):273-278.

19. Verma A. Epidemiology and clinical features of HIV-1 associated neuropathies. J Peripheral Nervous System. 2001; 6(1):8-13.

20. Brew BJ, Tisch S, Law M. Lactate concentrations distinguish between nucleoside neuropathy and HIV neuropathy. AIDS. 2003; 17(7):1094-1096.

21. Arenas-Pinto A, Bhaskaran K, Dunn D, Weller W. The risk of developing peripheral neuropathy induced by nucleoside reverse transcriptase inhibitors decreases over time: evidence from the Delta trial. Antiviral Therapy. 2008; 13(2):289-295

22. Lee H, Hanes J, Johnson KA. Toxicity of nucleoside analogues used to treat AIDS and the selectivity of the mitochondrial DNA polymerase. Biochemistry. 2003; 42(50):14711-14719.

23. Zhu Y, Antony JM, Martinez JA, Glerum DM, Brussee V, Hoke A, et al. Didanosine causes sensory neuropathy in an HIV/AIDS animal model: impaired mitochondrial and neurotrophic factor gene expression. Brain. 2007; 130(8):2011-2023

24. Peltier AC, Russell JW. Recent advances in druginduced neuropathies. Current Opinion Neurol. 2002; 15(5):633-638.

25. Canter JA, Haas DW, Kallianpur AR, Ritchie MD, Robbins GK, Shafer RW, et al. The mitochondrial pharmacogenomics of haplogroup T: MTND2* LHON4917G and antiretroviral therapy-associated peripheral neuropathy. Pharmacogenomics J. 2008; 8:71-77.

26. Berger AR, Arezzo JC, Schaumburg HH, Skowron G, Merigan T, Bozzette S, et al. 2, 3-dideoxycytidine (ddC) toxic neuropathy: a study of 52 patients. Neurology. 1993; 43(2):358-362
27. Crabb C. Protease inhibitors and risk of developing HIV-related sensory neuropathy. AIDS. 2004; 18 (14):N10

28. Kakuda JN. Pharmacology of nucleoside and nucleotide reverse transcriptase induced mitochondrial toxicity. Clinical Therapeutics. 2000; 22(6):685-705.

29. Moyle G. Toxicity of antiretroviral nucleoside and nucleotide analaogues. Drug Safety. 2000; 23(6): 467-481.

30. Feng JY, Johnson KA, Anderson KS. Insights into the molecular mechanism of mitochondrial toxicity by AIDS drugs. J Biol Chem. 2001; 276(26):23832-23837.

31. Piliero PJ, Fish DG, Preston S, Cunningham D, Kinchelow T, Salgo M, Qian J, Drusano GL. GuillainBarré syndrome associated with immune reconstitution. Clinical Infec Dis. 2003; 36(9):e111-4.

32. Piliero PJ, Fish DG, Preston S, Cunningham D, Kinchelow T, Salgo M, et al. Guillain-Barré syndrome associated with immune reconstitution. Clinical Infec Dis. 2003; 36(9):e111-e114.

33. Brannagan TH, Zhou Y. HIV-associated GuillainBarré syndrome. J Neurol Sci. 2003; 208(1):39-42.

34. Cornblath DR, McArthur JC, Kennedy PG, Witte AS, Griffin JW. Inflammatory demyelinating peripheral neuropathies associated with human T-cell lymphotropic virus type III infection. Ann Neurol. 1987; (21)1:32-40.

35. Centner CM, Bateman KJ, Heckmann JM. Manifestations of HIV infection in the peripheral nervous system. Lancet Neurol. 2013; 12(3):295-309.

36. Soliven B, Roos RP. Acute inflammatory demyelinating polyradiculoneuropathy. Peripheral Neuropathy. 1993; 2:1437-97.

37. Wulff EA, Wang AK, Simpson DM. HIVassociated peripheral neuropathy: epidemiology, pathophysiology and treatment. Drugs. 2000; 59 (6): 1251-1260.

38. Singer EJ, Valdes-Sueiras M, Commins D, Levine A. Neurologic presentations of AIDS. Neurologic Clinics. 2010; 28(1):253-75. 
39. Cornblath DR, McArthur JC, Kennedy PGE, Witte AS, Griffin JW. Inflammatory demyelinating peripheral neuropathies associated with human T-cell lymphotropic virus type III infection. Ann Neurol. 1987; 21(1):32-40

40. Simpson D, Estanislao L, Evans S, McArthur JC, Marcus K, Truffa M, et al HIV associated neuromuscular weakness syndrome. AIDS. 2004; 18 (10):1403-1412

41. Verma S, Misca E, Estanislao L, Simpson D. Neuromuscular complications in HIV. Current Neurol Neurosci Report. 2004; 4(1):62-67.

42. Berger JR, Simpson DM. The pathogenesis of diffuse infiltrative lymphocytosis syndrome: an AIDS related peripheral neuropathy. Neurol. 1998; 50(4): 855-857.

43. Gherardi RK, Chrétien F, Delfau-Larue MH, Authier FJ, Moulignier A, Roulliard-Dissoux D, et al. Neuropathy in diffuse infiltrative lymphocytosis syndrome: an HIV neuropathy, not a lymphoma Neurology. 1998; 50(4):1041-44.

44. Itescu S, Brancato LJ, Buxbaum J, Gregersen PK, Rizk CC, Croxson TS, Solomon GE, Winchester R. A diffuse infiltrative CD8 lymphocytosis syndrome in human immunodeficiency virus (HIV) infection: a host immune response associated with HLA-DR5. Ann Int Med. 1990; 112(1):3-10.

45. Moulignier A, Authier FJ, Baudrimont M, Pialoux G, Belec L, Polivka M, et al. Peripheral neuropathy in human immunodeficiency virus-infected patients with the diffuse infiltrative lymphocytosis syndrome. Ann Neurol. 1997; 41(4):438-45.

46. Kazi S, Cohen PR, Williams F, Schempp R, Reveille JD. The diffuse infiltrative lymphocytosis syndrome: clinical and immunogenetic features in 35 patients. AIDS. 1996; 10(4):385-92.

47. Tembl JI, Ferrier JM, Sevilla MT, Lago A, Mayordomo F, Vilchez JJ. Neurologic complications associated with hepatitis C infection. Neurology. 1999; 53(4):861-864.

48. Thomas DL, Shih JW, Alter HJ, Vlahov D, Cohn S, Hoover DR, et al. Effect of human immunodeficiency virus on hepatitis $\mathrm{C}$ virus infection among injecting drug users. J Infec Dis. 1996; 174(4):690-695.

49. Authier FJ, Pawlotsky JM, Viard JP, Guillevin L, Degos JD, Gherardi RK. High incidence of hepatitis C virus infection in patients with cryoglobulinemic neuropathy. Ann Neurol. 1993; 34(5):749-750.

50. Vassilopoulos D, Calabrese LH. Hepatitis C infection and vasculitis. Arthritis Rheumatism. 2002; 46 (3):585-597.

51. Miller RG, Storey JR, Greco CM. Ganciclovir in the treatment of progressive AIDS- related polyradiculopathy. Neurology. 1990; 40(4):569-574.

52. Lanska MJ, Lanska DJ, Schmidley JW. Syphilitic polyradiculopathy in an HIV-positive man. Neurology. 1988; 38(8):1297-1301.

53. Leger JM, Henin D, Belec L Mercier B, Cohen L, Bonche $\mathrm{P}$, et al. Lymphoma-induced polyradiculopathy in AIDS: Two cases. J Neurol. 1992; 239(3): 132-134.

54. So YT, Olney RK. Acute lumbosacral polyradiculopathy in acquired immunodeficiency syndrome: experience in 23 patients. Ann Neurol. 1994; 35(1):53-58.

55. Bazan C, Jackson C, Jinkins JR, Barohn RJ. Gadolinium-enhanced MRI in a case of cytomegalovirus polyradiculopathy. Neurology. 1991; 41 (9):1522-1523.

56. Kim YS, Hollander H. Polyradiculopathy due to cytomegalovirus: Report of two cases in which improvement occurred after prolonged therapy and review of the literature. Clinical Infec Dis. 1993; 17 (1):32-37.

57. Miller RF, Fox JD, Thomas P, Waite JC, Sharvell Y, Gazzard BG, et al. Acute lumbosacral polyradiculopathy due to cytomegalovirus in advanced HIV disease: CSF findings in 17 patients. J Neurol, Neurosurg \& Psych. 1996; 61(5):456-460.

58. So YT, Olney RK. Acute lumbosacral polyradiculopathy in acquired immunodeficiency syndrome: Experience in 23 patients. Ann Neurol 1994, 35(1):53-58. 
59. Said G, Goulon-Goeau C, Lacroix C, Feve A, Descamps H, Fouchard M. Inflammatory lesions of peripheral nerve in a patient with human $\mathrm{T}$ lymphotropic virus type I associated myelopathy. Ann Neurol. 1988; 24(2):275-277.

60. Nascimento OJ, Marques Jr W. Human T- cell leukemia virus (HTLV)-associated neuropathy. Hand book of Clinical Neurology 2013; 115:531.

61. Funamoto K, Takada K, Inoue K, Sawada Y, Araga $\mathrm{s}$, Takayashi K. Peripheral nerve involvement in HTLVI-associated myelopathy: report of a case. Japanese J Med. 1989; 28(6):762-4.

62. Harrison LH, Vaz B, Taveira DM, Taveira DM, Quinn TC, Gibbs CJ, et al. Myelopathy among Brazilians coinfected with human T-cell lymphotropic virus type I and HIV. Neurology. 1997; 48(1):13-18.
63. McArthur JC, Griffin JW, Cornblath DR, Griffin DE, TesorieroT, Kuncl R, et al. Steroid responsive myeloneuropathy in a man dually infected with HIV-I and HTLV-I. Neurology. 1990; 40(6):938-944.

64. McDougal JS, Hubbard M, Nicholson JK, Jones BM, Holman RC, Roberts J, et al. Immune complexes in the acquired immunodeficiency syndrome (AIDS); its relationship to disease manifestation, risk group, and immunologic defect. J Clinical Immunol. 1985; 5 (2):130-8.

65. Chaunu M, Ratinahirana H, Raphael M. The spectrum of changes on 20 nerve biopsies in patients with HIV infection. Muscle Nerve. 1989; 12(6):452-9.

66. Lipkin WI, Parry G, Kiprov D, Abrams D. Inflammatory neuropathy in homosexual men with lymphadenopathy. Neurology. 1985; 35(10):1479-1483.

\section{How to cite this article?}

Iyagba A, Onwuchekwa A. HIV- associated peripheral neuropathies: a review. Int J Med Res Rev 2016;4(11):20322038.doi:10.17511/ijmrr. 2016.i11.23. 